\title{
Acute pancreatitis complicating choledochal cysts in children
}

\section{Type of manuscript: Original article}

M Muthucumaru FRACS ${ }^{1}$, D Ljuhar MBBS ${ }^{2}$, G Panabokke MBBS $^{1}$, E Paul MSc ${ }^{3}$, R Nataraja FRCS ${ }^{1}, \mathrm{P}_{\text {Ferguson FRACS }}{ }^{1}, \mathrm{C}_{\text {Dagia }}{ }^{4}, \mathrm{~T}_{\text {Clarnette MD FRACS }}{ }^{1,2}$ and S King PhD FRACS ${ }^{2,5,6}$

(1) Department of Paediatric Surgery, Monash Medical Centre, 246 Clayton Road, Clayton, Australia, 3168.

(2) Department of Paediatric Surgery, The Royal Children's Hospital, 50 Flemington Road, Parkville, Victoria, Australia, 3052.

(3) Monash Centre for Health Research and Implementation, Monash University, Monash Medical Centre, 246 Clayton Road, Clayton, Australia 3168.

(4) Department of medical Imaging, The Royal Children's Hospital, 50 Flemington Road, Parkville, Victoria, Australia, 3052.

(5) Surgical Research, Murdoch Childrens Research Institute, 50 Flemington Road, Parkville, Victoria, Australia, 3052.

(6) Department of Paediatrics, The University of Melbourne, Melbourne, Victoria, Australia, 3052.

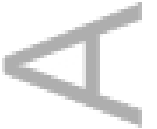

This is the author manuscript accepted for publication and has undergone full peer review but has not been through the copyediting, typesetting, pagination and proofreading process, which may lead to differences between this version and the Version of Record. Please cite this article as doi: $10.1111 /$ jpc. 13380

This article is protected by copyright. All rights reserved. 


\section{Corresponding author:}

Mathievathaniy Muthucumaru

Department of Paediatric Surgery,

Monash Medical Centre

246 Clayton Road

Clayton, Victoria

Australia, 3168

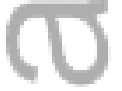

E-mail:kumaru70@yahoo.co.in

Fax: +61395946008

Phone: +6139594 6998

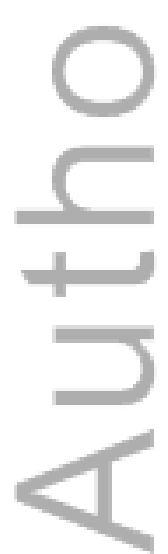

This article is protected by copyright. All rights reserved. 


\section{Abstract}

\section{Aims:}

To analyse the characteristics of patients with choledochal cysts presenting with acute pancreatitis.

\section{Methods:}

Multicenter retrospective review of all paediatric patients ( $<18$ years) with choledochal cysts managed over a 14-year period (2001 - 2014) at two tertiary paediatric surgical centers. Patient data was analysed for demographics, presentation, radiological classification of cyst type (Todani), operative interventions, complications and long-term follow-up.

\section{Results:}

A total of 49 patients with choledochal cysts were identified with 15 (31\%) being Type I fusiform, 18 (37\%) Type I cystic and 16 (32\%) Type IV-A. Seventeen (35\%) patients presented with acute pancreatitis, one having had an antenatally diagnosed choledochal cyst. Patients presenting with pancreatitis were older when compared to the non-pancreatitis group (5.1 years vs 1.2 years, $p=0.005)$. Nine out of $16(53 \%)$ patients with type IV-A cysts presented with pancreatitis compared to five (33\%) of Type I fusiform and three (17\%) of Type I cystic. There was however no statistically significant association between Todani types and the development of pancreatitis 
(Type I fusiform, $p=1.0$; Type I cystic, $p=0.063$; Type IV-A, $p=0.053$ ). The rate of complications was similar in both groups.

\section{Conclusion:}

Pancreatitis was a common presentation in children with a choledochal cyst, however there was no clear statistically significant association with Todani types and pancreatitis.

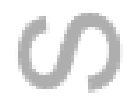

Key words: choledochal cyst; pancreatitis; cholangitis; cholestasis; pancreaticobiliary duct junction

This article is protected by copyright. All rights reserved. 


\section{Learning Points:}

\section{What is already known about this topic?}

(1) Previous studies have revealed an association between Todani type I (fusiform) and type IV-A cysts, and pancreatitis.

(2) There is a higher incidence of choledochal cysts in females.

(3) The risk of malignant transformation with choledochal cysts in children is extremely low.

\section{What this paper adds:}

(1) Pancreatitis was the most common mode of presentation in the postnatally diagnosed cohort.

(2) This study has not supported the association between Todani Type I and Type IV-A cysts and pancreatitis.

(3) Patients presenting with pancreatitis were significantly older than those without pancreatitis, suggesting the increasing risk of developing pancreatitis over time in patients with choledochal cysts.

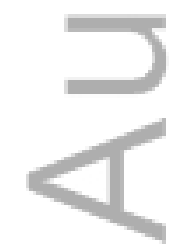

This article is protected by copyright. All rights reserved. 


\section{Introduction}

A choledochal cyst is a rare congenital dilatation of the biliary tree, with an incidence in Australia of 1:15000 births. It is three times more common in females compared with males. There is an unexplained higher incidence in certain Asian populations, approaching 1:1000 births. ${ }^{1}$ The current classification system, described by Todani et al. (1977), classified choledochal cysts into five major types, with subtypes in type I and type IV. ${ }^{2}$ Whilst the pathogenesis of choledochal cysts remain unclear, the most commonly accepted theory is based upon an anomalous pancreatico-biliary duct junction (APBDJ), leading to a long common channel. This allows for reflux of pancreatic enzymes into the common bile duct, leading to cholangitis and common bile duct dilatation, as well as the pancreatic duct which may lead to pancreatitis. ${ }^{3}$ Choledochal cysts have malignant potential, thus warranting complete excision in children and subsequent biliary reconstruction with hepaticojejunostomy or hepaticoduodenostomy.

The Todani types more commonly associated with APBDJ are type I fusiform, type IV-A, and type I cystic; hence the reported higher association of the first two types with pancreatitis. ${ }^{4}$ The reported incidence of pancreatitis in patients with choledochal cysts ranges from $0-76 \%{ }^{5}$

Ultrasound (USS) is the most common initial investigation to confirm the diagnosis of a choledochal cyst. Although ultrasound is accurate in identifying the 
cyst type, it does not identify the presence of APBDJ or any other complex pancreatic ductal anomaly. Therefore, for the definitive identification of APBDJ, magnetic resonance cholangiopancreatography (MRCP) is the gold standard.

Antenatally diagnosed cases of choledochal cysts are presumed to have an obstructive aetiology, thus explaining the cystic nature in the majority of cases. ${ }^{6}$ Postnatal presentations include jaundice, cholangitis, non-specific abdominal pain, abdominal mass and, rarely, perforation leading to biliary peritonitis. The purpose of this study was to analyse the characteristics of paediatric patients with choledochal cysts presenting with acute pancreatitis.

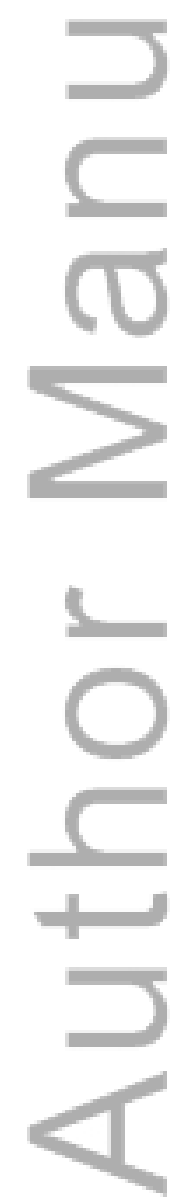

This article is protected by copyright. All rights reserved. 


\section{Materials and Methods}

A retrospective analysis of all choledochal cysts operated upon between 2001 and 2014 at two paediatric tertiary referral centres was undertaken. All patients underwent open choledochal cyst excisions, followed by Roux-en-Y hepaticojejunostomy. Only patients less than 18 years were included.

Patients were identified by searching hospital operating theatre databases and medical records, using appropriate ICD-9 and Medicare codes. Anatomical histopathology reports from The Royal Children's Hospital and Monash Medical Centre were subsequently retrieved. Patient records were reviewed, and collected data included: gender, ethnicity, mode of presentation, age at operation, cyst type (Todani classification), presence of APBDJ, and early and late complications. In instances where demographic and follow-up data were missing, families were contacted to clarify details.

All preoperative radiological investigations were identified, including USS, MRCP and/or endoscopic retrograde cholangiopancreatography (ERCP). The MRCP protocol for accurate identification of APBDJ is T2 weighted half-fourier acquisition singleshot turbo spin-echo (HASTE) sequences, with breath holding techniques. For the purposes of this retrospective analysis all imaging studies (USS, MRCP) were reviewed by one consultant radiologist to characterise cyst type and the presence of APBDJ leading to a long common channel. Acute pancreatitis was diagnosed with clinical findings of abdominal pain and an elevated lipase (> 204 IU/L) and/or amylase (>110 IU/L). 
Data was analysed using the SAS software version 9.4 (SAS Institute, Cary, NC, USA). Age and duration of follow-up were summarised using median and range. Categorical variables were expressed as counts and proportions. The risk factors for pancreatitis were compared across the Todani types using Fisher's exact test. In all cases a two sided p-values $<0.05$ was considered statistically significant. The study was approved by The Royal Children's Hospital Human Research Ethics Committee (DA001-2014-16).

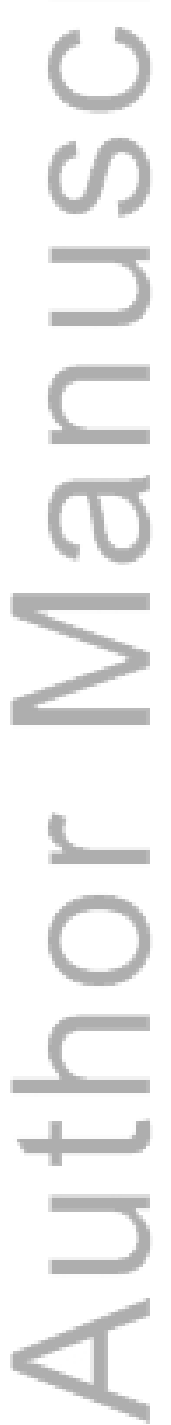

This article is protected by copyright. All rights reserved. 


\section{Results}

\section{Patient Demographics}

Fifty-one patients were identified, of which two were excluded due to a lack of data regarding cyst type and follow up (Table 1$)$. The majority $(38 / 49,78 \%)$ of patients was female. All included patients $(n=49)$ underwent choledochal cyst excision with Roux-en-Y hepaticojejunostomy. There were no cases of primary hepaticoduodenostomy reconstruction, nor laparoscopic choledochal cyst excision. The median age at operation was 2 years $(0.1-14.5)$. Those patients diagnosed antenatally underwent their operation at a significantly younger age $(0.85$ years versus 4.25 years, $p=0.0063)$. The majority of the patients were Caucasian. The median duration of follow-up was 7 years $(0.3-15$ years).

\section{Patient Presentation}

The majority $(37 / 49,76 \%)$ of choledochal cysts were diagnosed postnatally. A total of 17 patients (35\%) presented with acute pancreatitis (Table 2). All but one case of pancreatitis occurred in those whom the choledochal cyst was diagnosed postnatally. Of the 12 antenatally diagnosed cases, one patient $(8 \%)$ presented with pancreatitis at the age of 20 months, and four patients (33\%) presented with jaundice. Other modes of presentation include uncomplicated cholestasis, nonspecific abdominal pain, an incidental diagnosis on USS, biliary peritonitis, or the classic triad of abdominal pain, jaundice and an abdominal mass (Table 2).

\section{Cyst types and the presence of APBDJ}


All patients underwent preoperative radiological investigations. Ultrasound was performed in all 49 patients, with 42 patients proceeding to further imaging (MRCP - 31/42, ERCP - 11/42). 15/42 (31\%) were Type I fusiform cysts, 18/42 (37\%) were Type I cystic and 16/42 were (32\%) Type IV-A. Pre-operative MRCP demonstrated an APBDJ in 16/31 (Figure 1). Two patients initially reported as Type IV-B cysts were re-reported as Type IV-A upon review by single independent radiologist.

\section{Pancreatitis}

Those presenting with pancreatitis were significantly older at the time of initial presentation than those without pancreatitis in both the overall cohort as well if only the postnatally diagnosed patients were examined (overall cohort 5.1 vs 1.2 years, $p=0.005$; postnatally diagnosed only 5.5 versus 1.6 years, $p=0.005$ ). Females predominated in both groups, though this was not statistically significant between the groups $(p=0.725)$. Patients with Type IV-A cysts represented the largest proportion of cyst types who presented with pancreatitis (53\%), however there was no statistically significant increase in pancreatitis between type of cyst (Type I fusiform, p=1.0; Type I cystic, p=0.063; Type IV-A, p=0.053). (Table 3).

\section{Complications}

Four early complications were identified. Two patients experienced a postoperative bile leak, one of whom had presented with pancreatitis (both Todani Type I fusiform). Both patients were managed conservatively. One patient experienced 
dislodgement of the drainage tube (Todani Type IV-A), whilst another patient developed an ileo-ileocolic intussusception two weeks post-operatively that required a laparotomy and resection of ischaemic ileum (Todani Type I cystic).

Seven delayed complications were identified (Table 4). Five patients experienced recurrent abdominal pain, without a clinical diagnosis of pancreatitis or cholangitis. Of these patients, three had abnormal findings on repeat MRCP (including two residual cysts and one with dilatation of the pancreatic duct) and two had normal blood biochemistry and normal imaging studies. The remaining two patients presented with cholangitis. One patient was found on ultrasound to have residual choledochal cyst and underwent a further laparotomy with cyst resection. The remaining patient had normal findings on imaging. At the completion of the study no patient had presented with post-operative pancreatitis.

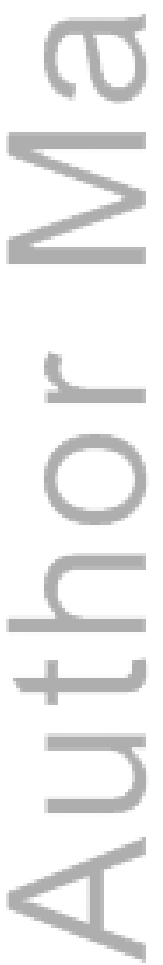

This article is protected by copyright. All rights reserved. 


\section{Discussion}

The presentation of acute pancreatitis complicating a choledochal cyst was first described in $1969 .{ }^{7}$ In our series, we have demonstrated acute pancreatitis as the presenting complaint in more than one third of the 49 patients, highlighting the importance of this presentation for a rare condition. Interestingly, the incidence of pancreatitis was five times higher in the current study compared with a previous report from one of our institutions. ${ }^{8}$ This changing pattern may be due to increased utilisation of diagnostic tests performed in patients with abdominal pain, or represent a true increase in the incidence of pancreatitis as a presentation.

Fujishiro et al. ${ }^{5}$ reported a significant increase in the incidence of pancreatitis in those patients with Type I fusiform and Type IV-A cysts. In our cohort, we were unable to demonstrate an association between these cyst types and pancreatitis. While the cohort represents one of the largest published series for choledochal cysts, the study may be underpowered and as such may represent a Type II error. It has been suggested that the increased association of Type I fusiform and Type IV-A with pancreatitis is most likely due to the presence of APBDJ. ${ }^{4}$ The role for APBDJ as a key predisposing factor for pancreatitis complicating choledochal cyst was proposed by Miyano et al. following his experimental study of 40 puppies. ${ }^{9}$ In our cohort, the presence of APBDJ was confirmed in only half of the patients who underwent an MRCP. Of the documented cases 56\% presented with pancreatitis. The technique of MRCP has more than $96-100 \%$ detection rates for cyst types; however, its diagnostic accuracy for APBDJ is less predictable. ${ }^{10}$ Accuracy has been improved recently by newer imaging sequences, including secretin-enhanced 
MRCP, 3-dimensional fast spin-echo, half fourier acquisition single shot turbo spinecho sequence, single-slice and maximum intensity projection (MIP) slice. ${ }^{10}$

In our cohort of patient a quarter were diagnosed antenatally. Only one patient with an antenatal diagnosis presented with pancreatitis at the age of 20 months. This patient had been lost to follow up. This finding is comparable with the literature, in which antenatally diagnosed patients have a low incidence of pancreatitis due to the earlier age at operation. ${ }^{5}$ This presents justification for elective surgery after 6 months of age given the increasing incidence of antenatally diagnosed patients.

All the cases presenting with pancreatitis had a six week interval between the last episode of pancreatitis and cyst excision to prevent early complications. In the current study, bile leak following cyst excision was no higher in the pancreatitis group compared to the non-pancreatitis group. As such, the six week interval is most likely adequate enough to prevent early complications in patients with pancreatitis. Our follow up did not reveal any cases of post-excision pancreatitis. A residual cyst was found to be the cause of recurrent cholangitis in one case, emphasizing the need for complete cyst excision, both for malignancy risk and complete symptom control.

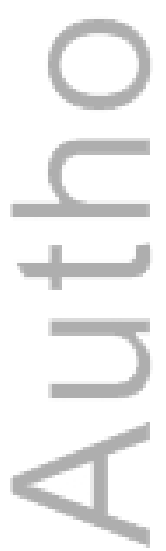

This article is protected by copyright. All rights reserved. 


\section{Conclusion}

Acute pancreatitis complicating choledochal cysts was a common mode of presentation in our cohort of paediatric patients. This warrants careful imaging of the biliary tree in cases of pancreatitis in children. We have shown that neither the Todani Type IV-A cyst nor Type 1 fusiform or cystic cysts were a risk factor for pancreatitis.

$=$

1

13

$\infty$

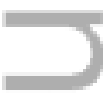
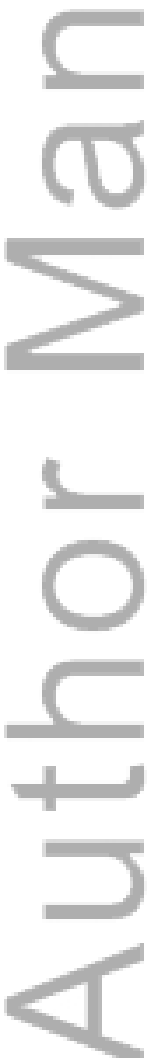

This article is protected by copyright. All rights reserved. 


\section{References}

1. Singham J, Yoshida EM, Scudamore $\mathrm{CH}$. Choledochal cysts: Classification and pathogenesis. J Can Chir 2009;52:434-40.

2. Todani T, Watanabe $\mathrm{Y}, \mathrm{N}$ arusue $\mathrm{M}$, et al. Congenital bile duct cysts:

Classification,operative procedures, and review of 37 cases including cancer arising from choledochal cyst. Am J Surg 1977;134:263-69.

3. Babbitt DP, Starshak RJ, Clemett AR. Choledochal cyst: a concept of etiology. Am J Roentgenol Radium Ther Nucl Med 1973;119:57-62.

4. Todani T. Congenital choledochal dilatation: Classification, clinical features, and long term results. J Hep Bil Pancr Surg 1977; 4:276-82.

5. Fujishiro J, Masumoto K, Urita Y, et al. Pancreatic complications in pediatric choledochal cysts. J Pediatr Surg 2013; 48:1897-1902.

6. Davenport M, Basu R. Under pressure: choledochal malformation manometry. J Pediatr Surg 2005; 40:331-35.

7. Cuschieri A, Davies RS. Acute pancreatitis complicating a choledochal cyst. Br Med J 1969;3:698.

8. Taylor RG, Auldist AW. Choledochal cyst presenting as acute pancreatitis. ANZ J Surg 1985;55:611-12.

9. Yamashiro Y, Miyano T, Suruga K, et al. Experimental study of the pathogenesis of choledochal cyst and Pancreatitis, with special reference to the role of bile acids and pancreatic enzymes in the anomalous choledocho-pancreatico ductal junction. $\mathrm{J}$ Pediatr Gastroen Nutrition 1984;3: 721-27. 
10. Sacher VY, Davis JS, Sleeman D et al. Role of magnetic resonance cholangiopancreatography in diagnosing choledochal cysts: case series and review. World J Radiol 2013;5:304-312

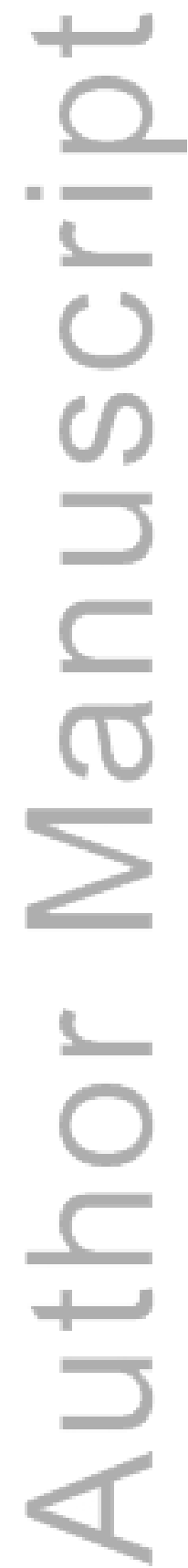

This article is protected by copyright. All rights reserved. 


\section{Tables}

Table 1: Patient demographics $(n=49)$

\begin{tabular}{|ll|}
\hline Gender & \\
Male & $11(22.4 \%)$ \\
Female & $38(77.6 \%)$ \\
\hline Age at operation (years) & $2(0.1-14.5)$ \\
Median (range) & \\
\hline $\begin{array}{l}\text { Ethnicity } \\
\text { Caucasian }\end{array}$ & $35(71.4 \%)$ \\
Indian & $6(12.2 \%)$ \\
Other & $4(8.2 \%)$ \\
\hline Todani types & $4(8.2 \%)$ \\
I (fusiform) & $16(30.6 \%)$ \\
I (cystic) & $18(32.7 \%)$ \\
IV-A & $16 \%)$ \\
\hline
\end{tabular}

This article is protected by copyright. All rights reserved. 
Table 2: Presenting features

\begin{tabular}{|l|l|l|l|}
\hline & Antenatal (n = 12) & Postnatal (n = 37) & Total (n = 49) \\
\hline Abdominal pain & & & \\
Noncreatitis & $1(8.3 \%)$ & $16(43.2 \%)$ & $17(34.7 \%)$ \\
Asymptomatic & 0 & $8(21.6 \%)$ & $8(16.4 \%)$ \\
Jaundice & $7(58.3 \%)$ & $3(8.1 \%)$ & $10(20.4 \%)$ \\
\hline Abdominal pain, jaundice, & 0 & $7(18.9 \%)$ & $11(22.5 \%)$ \\
abdominal mass & $4(33.3 \%)$ & $1(2.7 \%)$ & $1(2.0 \%)$ \\
\hline Cholangitis & 0 & $1(2.7 \%)$ & $1(2.0 \%)$ \\
\hline Perforation & 0 & $1(2.7 \%)$ & $1(2.0 \%)$ \\
\hline
\end{tabular}

This article is protected by copyright. All rights reserved. 
Table 3: Patients with and without pancreatitis

\begin{tabular}{|l|l|l|l|}
\hline & Patients with pancreatitis $(n=17)$ & Patients without pancreatitis $(n=32)$ & $P$ value \\
\hline Age (years) & $5.13(1.18-14.54)$ & $1.17(0.05-8.33)$ & 0.005 \\
\hline Gender & $3(18 \%)$ & $8(32 \%)$ & 0.75 \\
Male & $14(82 \%)$ & $24(75 \%)$ & \\
Female & $(5 / 15(33 \%)$ & $10 / 15(67 \%)$ & 1.00 \\
\hline Todani & $3 / 18(17 \%)$ & $15 / 18(83 \%)$ & 0.063 \\
I fusiform & $9 / 16(53 \%)$ & $7 / 16(47 \%)$ & 0.053 \\
I cystic & & & \\
IV-A & & & \\
\hline
\end{tabular}

This article is protected by copyright. All rights reserved. 
Table 4: Delayed complications $(n=7)$

\begin{tabular}{|llll|}
\hline Complications & Pancreatitis & Todani type & Cause found \\
Cholangitis - - episodes & Yes & IV-A & Residual cyst \\
Cholangitis & Yes & I cystic & No \\
Recurrent abdominal pain & No & I fusiform & Residual cyst \\
Recurrent abdominal pain & Yes & IV-A & Dilated pancreatic duct \\
Recurrent abdominal pain & No & I cystic & Residual cyst \\
Recurrent abdominal pain & Yes & I cystic & No \\
Recurrent abdominal pain & Yes & I fusiform & No \\
\hline
\end{tabular}

This article is protected by copyright. All rights reserved. 


\section{Figures}

Figure 1: Abnormal biliary-pancreatic duct (long common channel) and pancreatitis

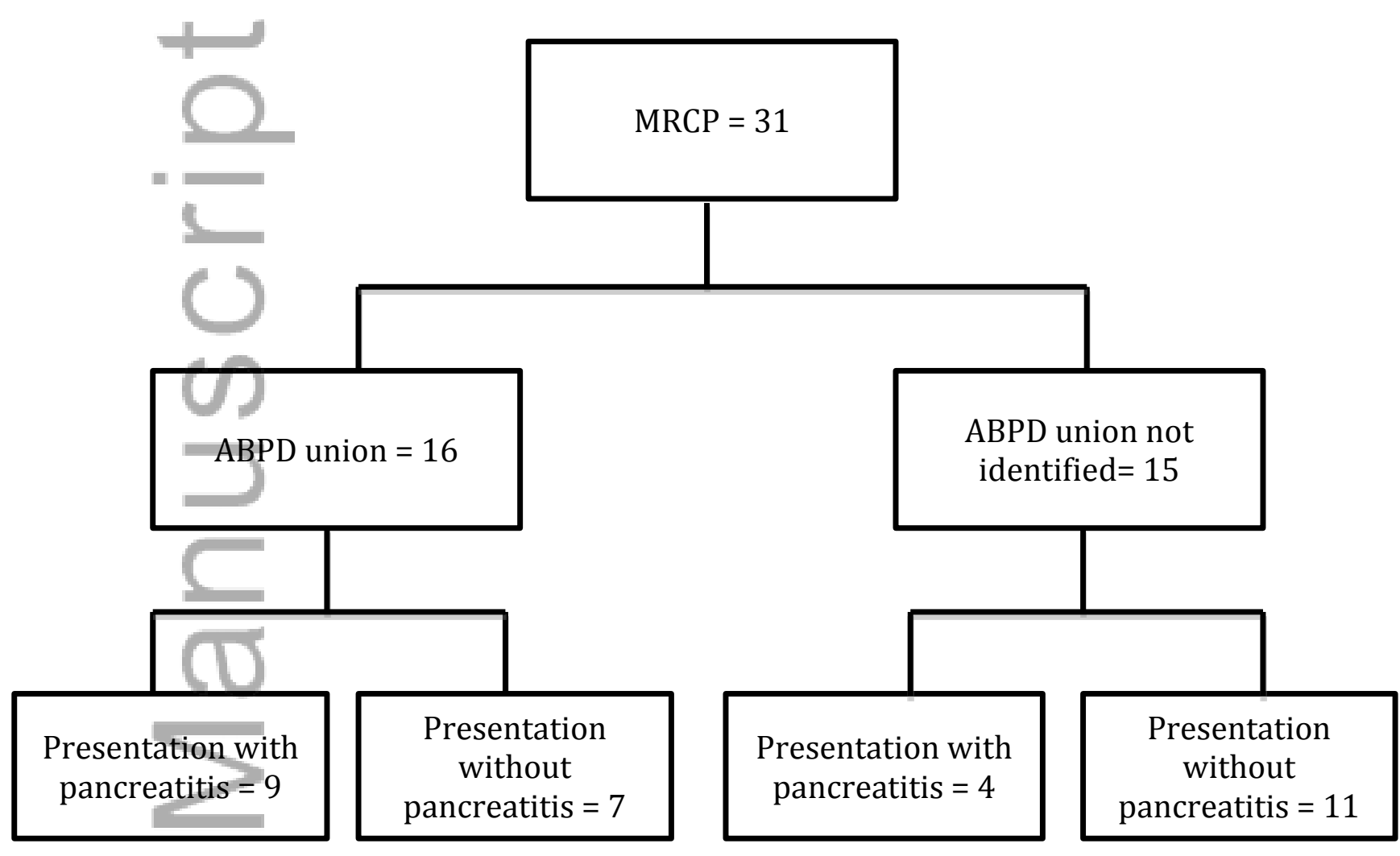

This article is protected by copyright. All rights reserved. 


\section{University Library}

\section{- M M N E R VA A gateway to Melbourne's research publications}

Minerva Access is the Institutional Repository of The University of Melbourne

Author/s:

Muthucumaru, M;Ljuhar, D;Panabokke, G;Paul, E;Nataraja, R;Ferguson, P;Dagia, C;Clarnette, T;King, S

Title:

Acute pancreatitis complicating choledochal cysts in children

Date:

2017-03-01

Citation:

Muthucumaru, M., Ljuhar, D., Panabokke, G., Paul, E., Nataraja, R., Ferguson, P., Dagia, C., Clarnette, T. \& King, S. (2017). Acute pancreatitis complicating choledochal cysts in children. JOURNAL OF PAEDIATRICS AND CHILD HEALTH, 53 (3), pp.291-294. https:// doi.org/10.1111/jpc. 13380.

Persistent Link:

http://hdl.handle.net/11343/291818 